\title{
Computational Exploration of How Enzyme XimE Converts Natural S-Epoxide to Pyran and R-Epoxide to Furan
}

Chuchu Jiang ${ }^{1}$, Bei-Bei He ${ }^{1}$, Rosalinda L. Zhao ${ }^{2}$, Min-Juan $\mathrm{Xu}^{3}, \star$ K. N. Houk ${ }^{2} \star$ Yi-Lei Zhao $^{1}$ *

1. State Key Laboratory of Microbial Metabolism, Joint International Research Laboratory of Metabolic and Developmental Sciences, School of Life Sciences and Biotechnology, Shanghai Jiao Tong University, Shanghai 200240, P. R. China.

2. Department of Chemistry and Biochemistry, University of California, Los Angeles, California 90095 , United States.

3. Key Laboratory of Systems Biomedicine (Ministry of Education), Shanghai Centre for Systems Biomedicine, Shanghai Jiao Tong University, Shanghai 200240, P. R. China.

Corresponding authors' email addresses:

minjuanxu@sjtu.edu.cn

houk@chem.ucla.edu

yileizhao@sjtu.edu.cn 


\section{Contents}

Figure S1. The HPLC traces for nonenzymatic and enzymatic epoxide ring opening...............S3

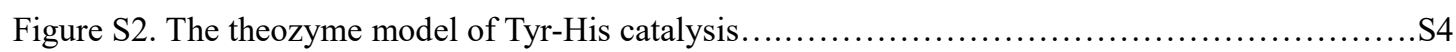

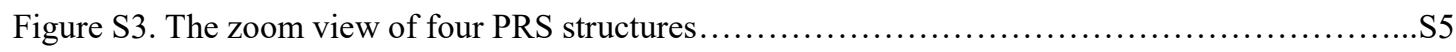

Figure S4. The ONIOM transition structures in which Y46 acts as a HB donor.....................S6

Figure S5. The dynamic effect of the four transition states in the TS-enzyme complexes..............S7

Figure S6. The superposition of the TS-enzyme snapshots and ONIOM-optimized structures..........S8

Figure S7. The IRC energy profiles for the four transition states................................. 9

Figure S8. The 10ns MD simulations of the product-enzyme complexes...................... S10

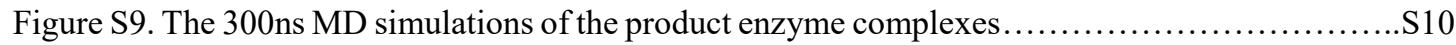

Geometries of the small molecular models.............................................. S11-S14 


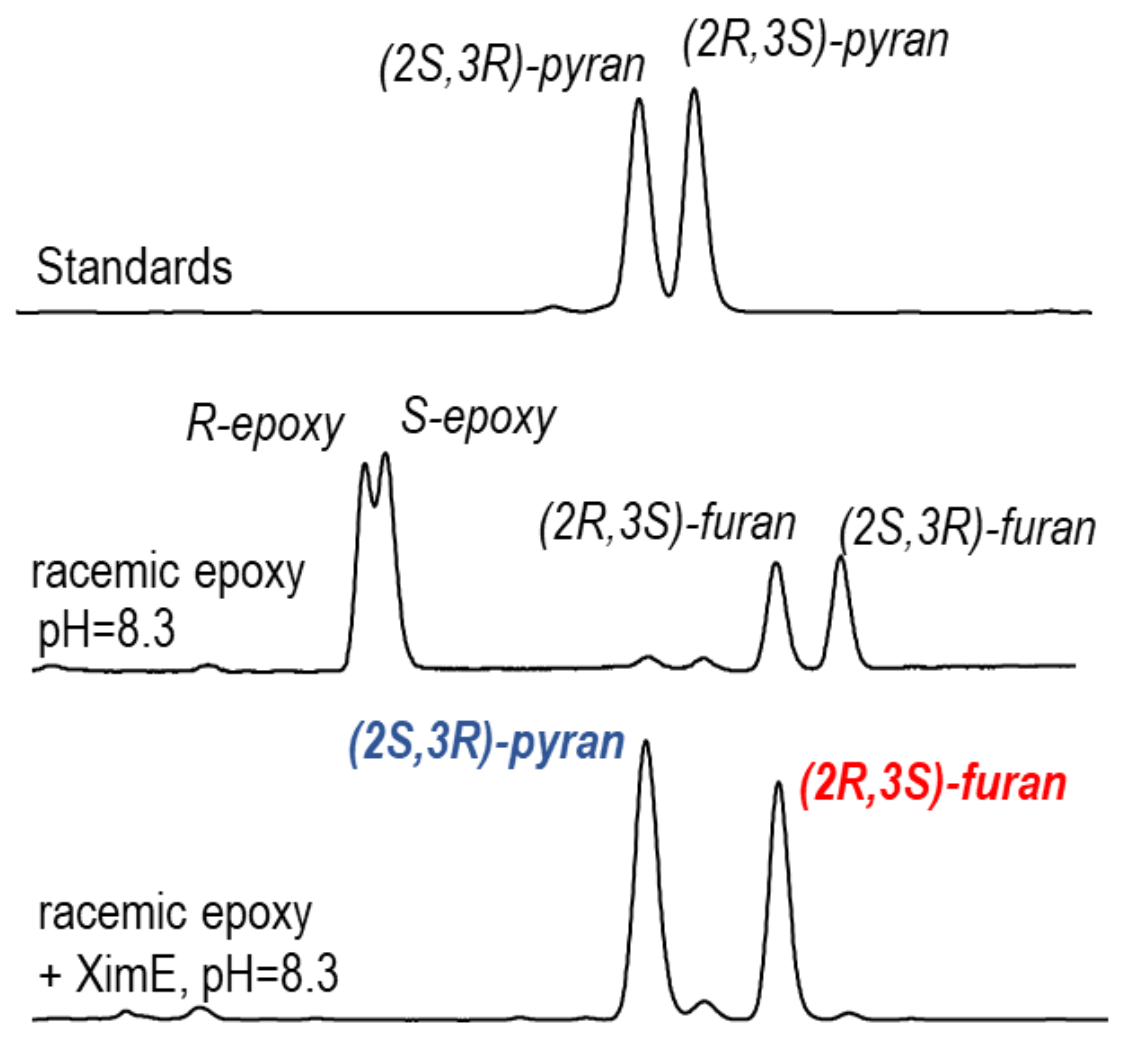

Figure S1. The HPLC traces of standards pyranocoumarins, and of reaction mixtures of racemic epoxys in the presence and absence of $40 \mathrm{nM} \mathrm{XimE}$ at $\mathrm{pH} 8.3$ in three minutes at $30{ }^{\circ} \mathrm{C}$. (Both the conversions of R-epoxide to $(2 R, 3 S)$-furan and S-epoxide to $(2 S, 3 R)$-pyran were accelerated in the XimE-catalysis)

Note: One might argue that the high ratio of $(2 R, 3 S)$-furan and $(2 R, 3 S)$-pyran attributed to the faster pyran-formation from the $R$-epoxide as in the spontaneous epoxide ring opening. However, the spontaneous cyclization occurred much slower than the XimE-catalyzed cyclization at $\mathrm{pH} 8.3$ - two thirds of racemic epoxy compounds were left in the spontaneous reaction mixture in the same reaction time. Comparatively, the pyran-formation of $S$-epoxide was accelerated even more efficiently than the furan-formation of $R$-epoxide, probably by onemagnitude (enzyme enhancements: 100-fold for S-epoxy pyran-cyclization, 10-fold for $R$ epoxy furan-cyclization). Owing to the chemical instability of the epoxides and the competitivity between the spontaneous and catalyzed epoxide ring opening, there was a technique difficulty to measure the exact $\mathrm{k}_{\mathrm{cat}}$ and $\mathrm{K}_{\mathrm{m}}$ for the two enantiomeric epoxides.

Experimental details: The organic synthesis of racemic epoxides uses a previous reported $\mathrm{VO}$ (acac)2/ tert-butyl hydroperoxide(TBHP) (1.5 mol\% / 1.3 eqiv) system. Briefly, $25.0 \mathrm{mg} 3-$ geranyl-4-hydroxbenzoic acid, $0.5 \mathrm{mg} \mathrm{VO}(\mathrm{acac}) 2$ and $23 \mu \mathrm{L} \mathrm{TBHP}$, and $1.8 \mathrm{~mL} \mathrm{CH} 2 \mathrm{Cl} 2$ were mixed and incubated under $40{ }^{\circ} \mathrm{C}$ in oil bath for 3 hours with gently stirring, and then immediately frozen in $-80{ }^{\circ} \mathrm{C}$ for future use. (Reference: Alessandra Lattanzi \& Arrigo Scettri, $\mathrm{VO}(\mathrm{acac}) 2 / \mathrm{TBHP}$ catalyzed epoxidation of 2-(2-alkenyl)phenols. Highly regio- and diastereoselective oxidative cyclization to 2,3-dihydro-benzofuranols and 3-chromanols, Synlett. 2002, 6, 942-946.) 


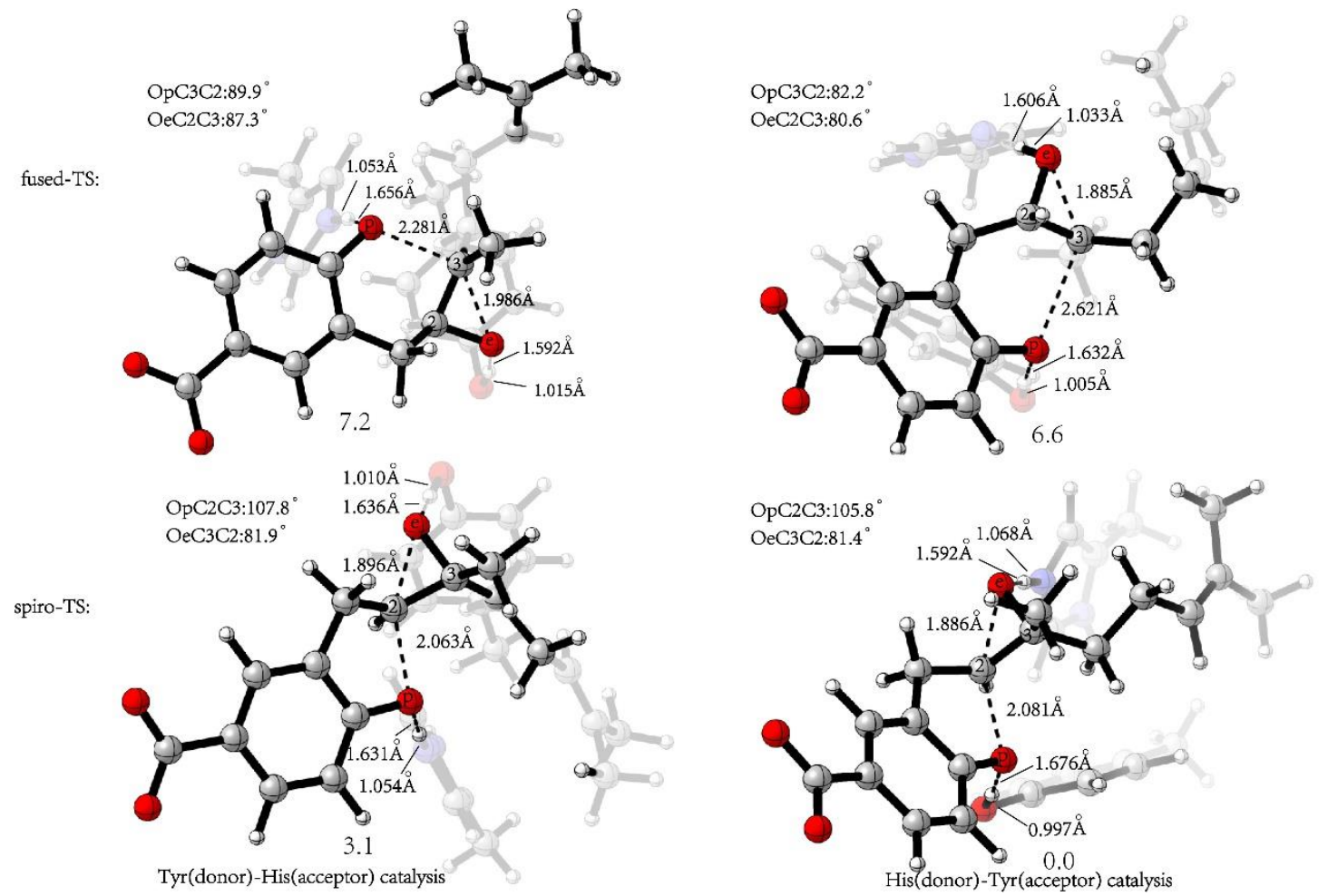

Figure S2. The lowest-energy transition structures in a theozyme model of general acid-base catalysis with either Tyr(donor)-His(acceptor) or His(donor)-Tyr(acceptor) catalysis, which is found to be unreal for XimE and higher in reaction barrier compared to the Glu-His catalysis.

Compared with the Glu(donor)-His(acceptor) catalytic mode, the reaction barriers of the $\operatorname{Tyr}($ donor) His(acceptor) catalytic mode is higher by 3.9 and $3.4 \mathrm{kcal} / \mathrm{mol}$ for the fused- and spiro-transition states, respectively. In the His(donor)-Tyr(acceptor) catalytic mode, the reaction barrier of fused-TS is higher by $3.2 \mathrm{kcal} / \mathrm{mol}$, but spiro-TS is lower by $1.5 \mathrm{kcal} / \mathrm{mol}$ (but it is unlikely to have a tyrosine anion). In short, proton donation from Try46 is unfavored owing to its relatively high $\mathrm{pKa}$, and its phenoxy group involves in the hydrogen bonding network with both epoxide and alcohol in both the pre-reaction state and post-reaction states. So, Y46 contributes in binding the ligands in the substrate-enzyme and productenzyme complexes. In the ONIOM calculations, Y46 was calculated in the QM region to include its contribution to the reaction potential energy surface. 


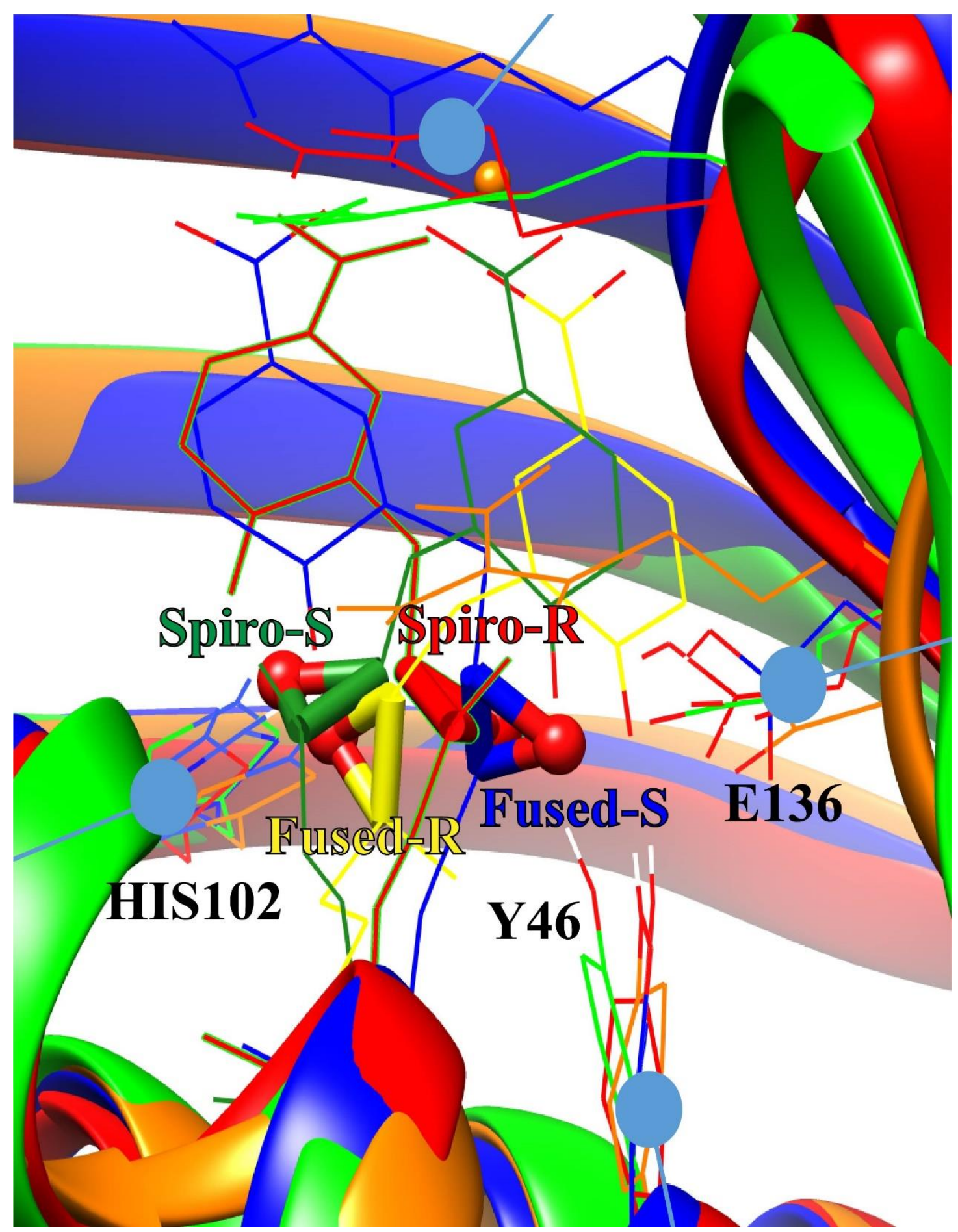

Figure S3. The zoom view of four PRS structures in Figure 4A. 


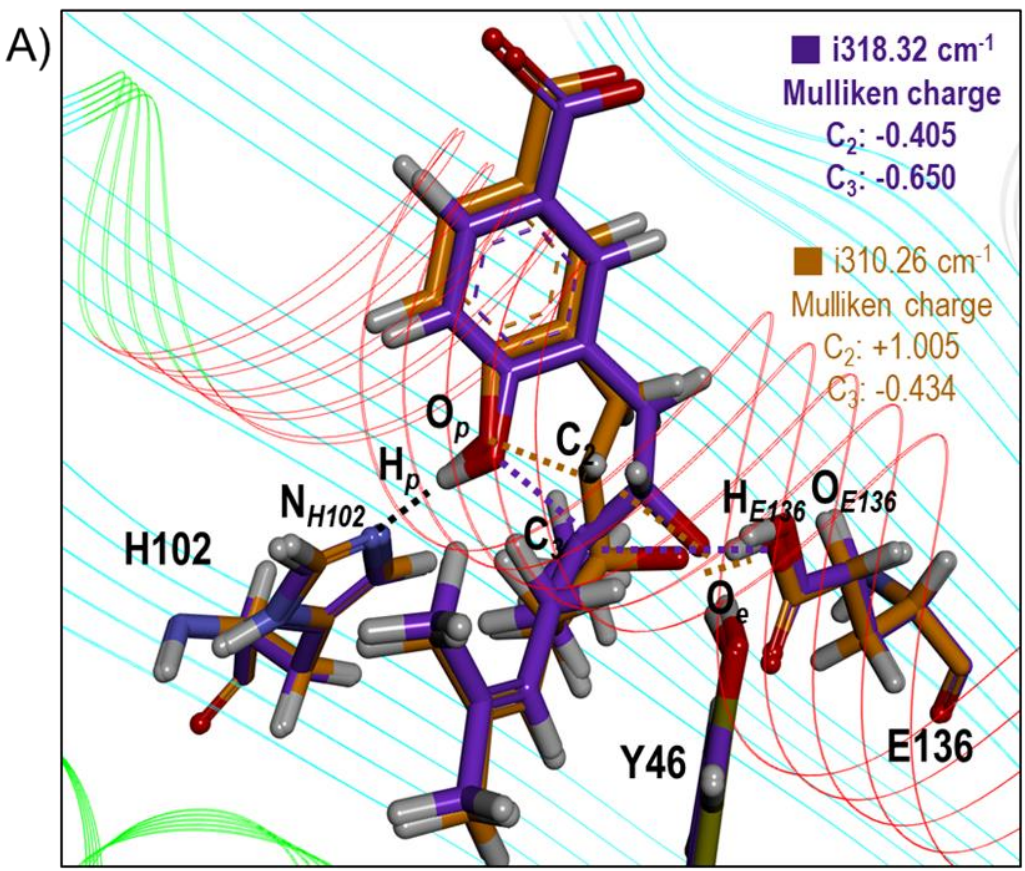

Starting geometry: "fused-" pre-reaction state of S-epoxide fused-TS spiro-TS

B)

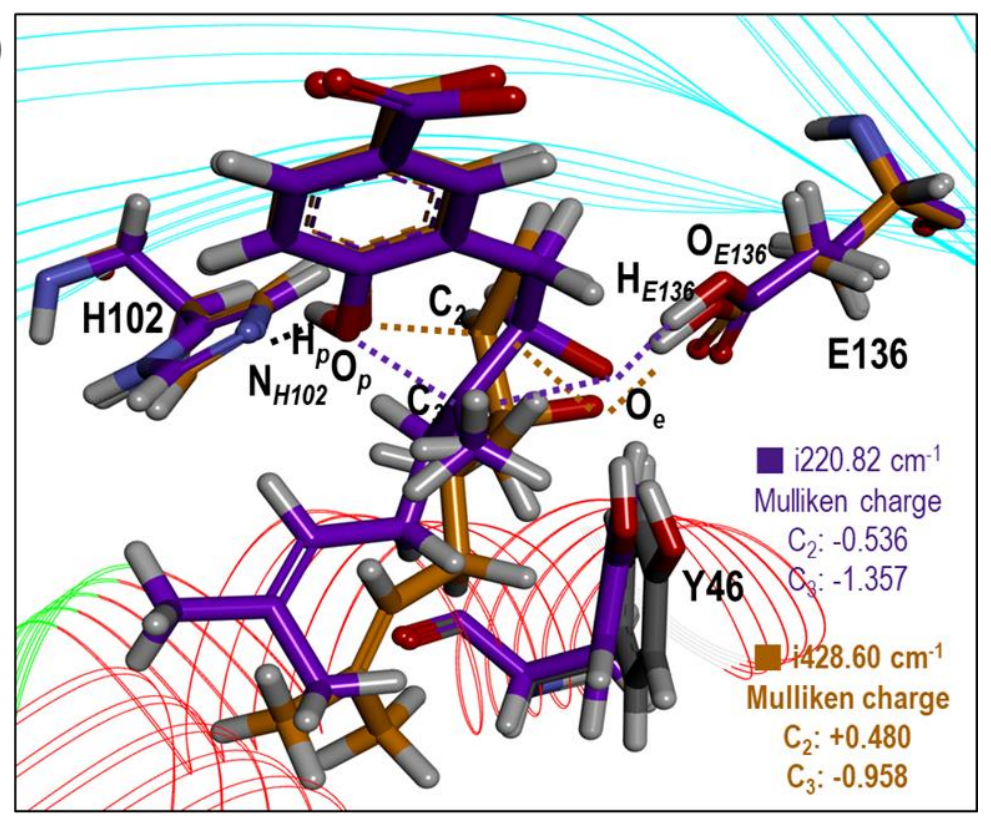

Starting geometry: "spiro-" pre-reaction state of R-epoxide spiro-TS $\square$ fused-TS

Figure S4. The transition structures optimized with the ONIOM $(\omega \mathrm{B} 97 \mathrm{X}-\mathrm{D} / 6-31+\mathrm{G}(\mathrm{d})$ :AMBER) method, in which Y46 acts as a hydrogen bonding donor to assist the epoxide ring open, of (A) Fusedand Spiro-TSs of S-epoxide, and (B) Spiro- and Fused-TSs of R-epoxide, respectively. 

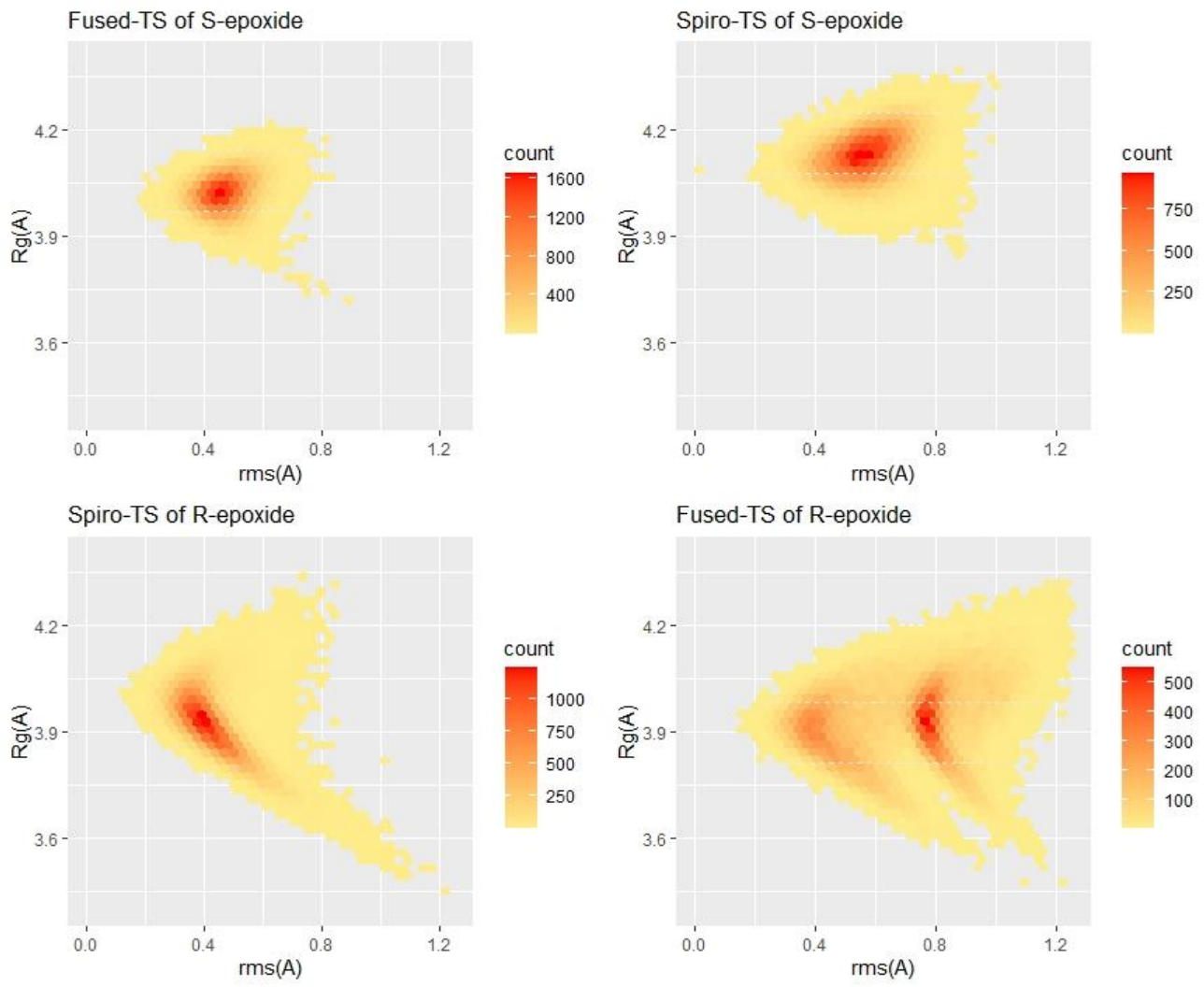

Figure S5. The dynamic effect of the four transition states in the TS-enzyme complexes. The substrate radius of gyration $(\mathrm{Rg})$ and root mean square (rms) deviation from the ONIOM-optimized transition structures in the $100 \mathrm{~ns} \mathrm{MD}$ simulation with the transition state constraints, i.e. retaining the partially forming and breaking C-O bond distances, as in (A) Fused-TS and (B) Spiro-TS of S-epoxide, and (C) Spiro-TS and (D) Fused-TS of R-epoxide, respectively. 


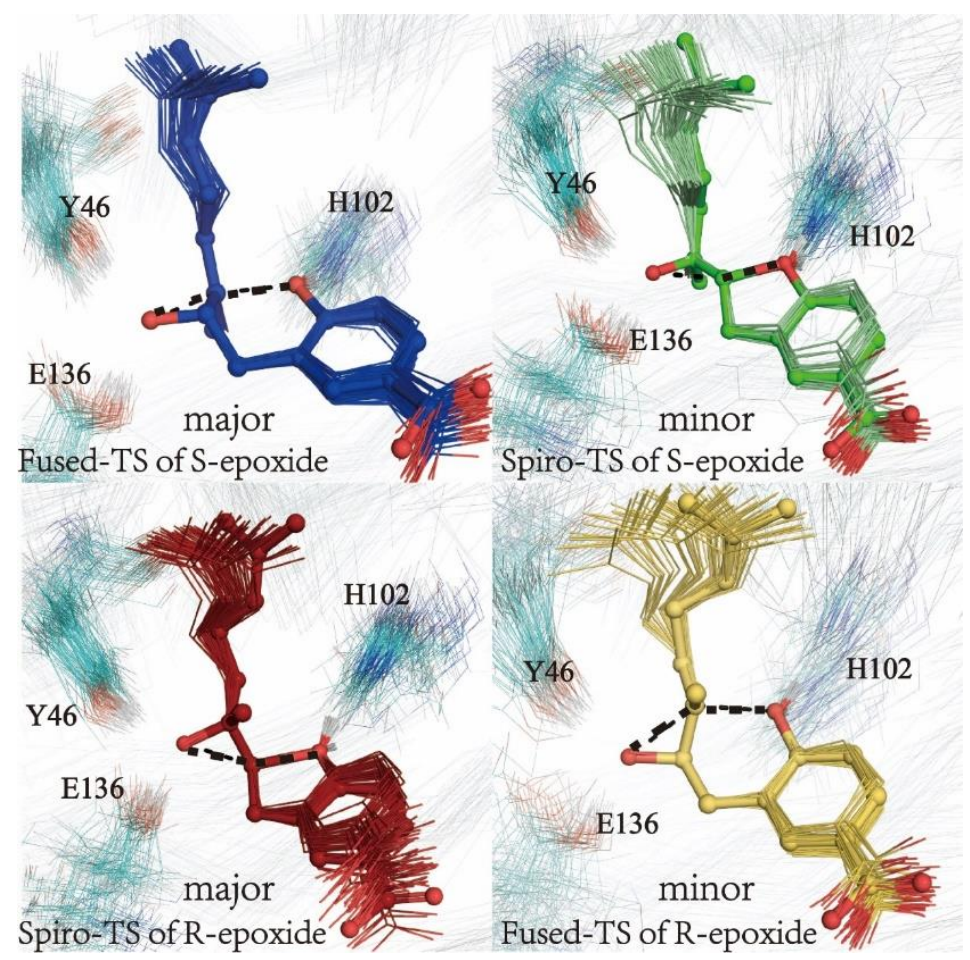

Figure S6. Fifty snapshots of the transition state MD simulation, whose geometries were randomly extracted from the $100 \mathrm{~ns}$ trajectories. The ONIOM-optimized substrate structures are shown in stickball representation, and substrate structures in the MD snapshot ensemble is shown in stick representation, and the rest of the TS-enzyme complex is shown in wire representation, using the same color patterns in the text. 

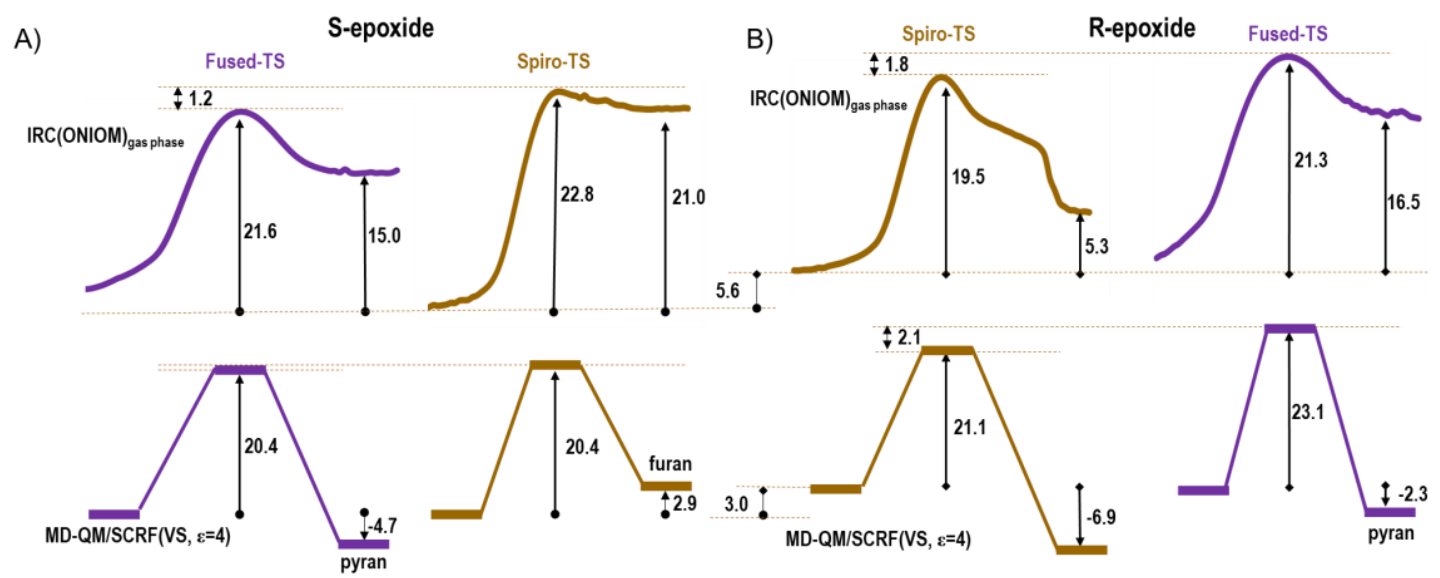

Figure S7. The IRC energy profile of the fused- and spiro-TS of S-epoxide (A) and R-epoxide (B) in the ONIOM "gas-phase" calculation with explicit water solvation (top), and the energies of at the saddle point and two ending points re-evaluated with the MD-QM/SCRF(VS) method, $\omega B$ 97X-D/6$31+\mathrm{G}(\mathrm{d})(\mathrm{CPCM}$, electric constant $=4.0)$ using movable protons of $\mathrm{H}_{\mathrm{p}}$ and $\mathrm{H}_{\mathrm{E} 136}$ for the pyran and furan product (bottom).(Note that the $\mathrm{QM} / \mathrm{SCRF}(\mathrm{VS})$ calculations indicate that the proton transfer did not occur before the transition states but after the transition states.) 

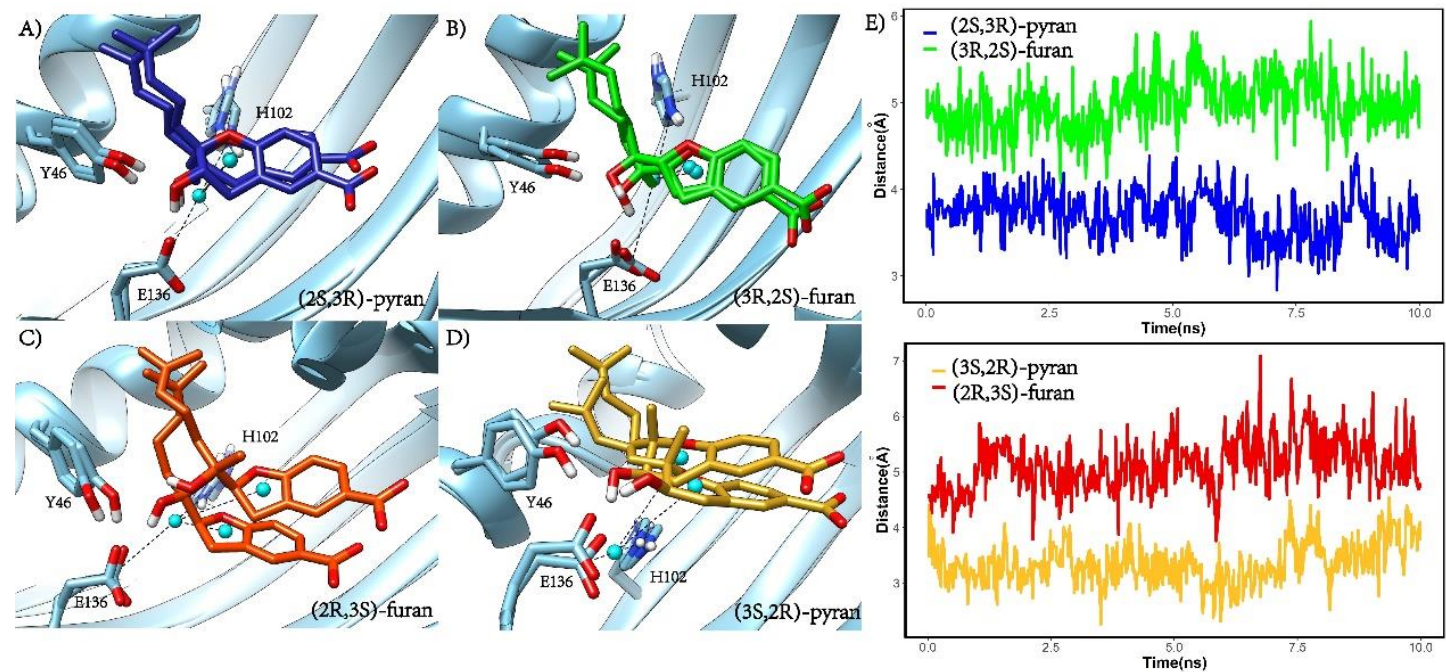

Figure S8. The 10ns MD simulation of product-enzyme complexes, with initial geometries from the ONIOM calculation after the epoxide ring open of (A) (2S,3R)-pyran and (B) (3R,2S)-furan of S-epoxide, and (C) (2R,3S)-furan and (D) (3S,2R)-pyran of R-epoxide, respectively. The time-dependent distances between the CD@E136-NE@H102 center and pyrano-/furano-ring center were plotted in (E). (top, Sepoxide; bottom, R-epoxide).
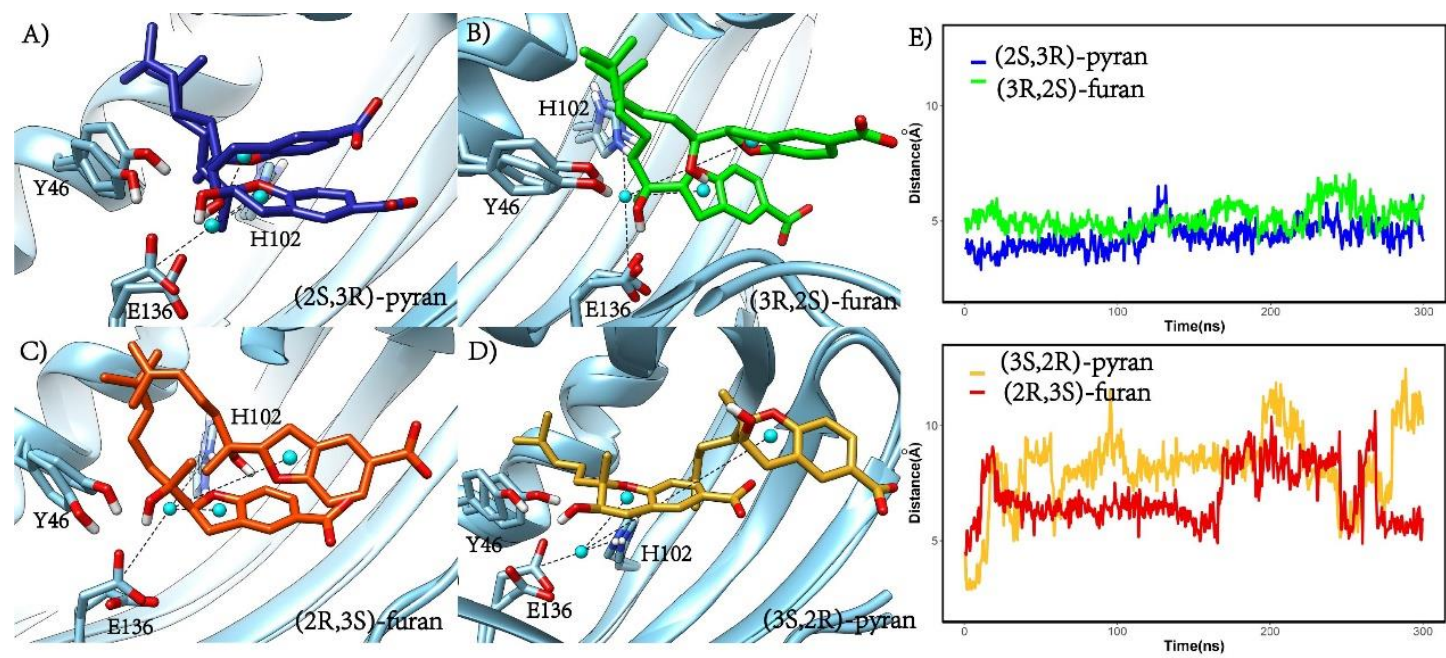

Figure S9. The 300ns MD simulation of product-enzyme complexes, with initial geometries from the ONIOM calculation after the epoxide ring open of (A) (2S,3R)-pyran and (B) (3R,2S)-furan of S-epoxide, and (C) (2R,3S)-furan and (D) (3S,2R)-pyran of R-epoxide, respectively. The time-dependent distances between the CD@E136-NE@H102 center and pyrano/furano-ring center were plotted in (E). (top, Sepoxide; bottom, R-epoxide). 
Sum of electronic and zero-point Energies=
Sum of electronic and thermal Energies=

-960.896375
-960.875329

-960.875329
-960.874385

of electronic and thermal Free Energies

0.946845

\section{Pyran}

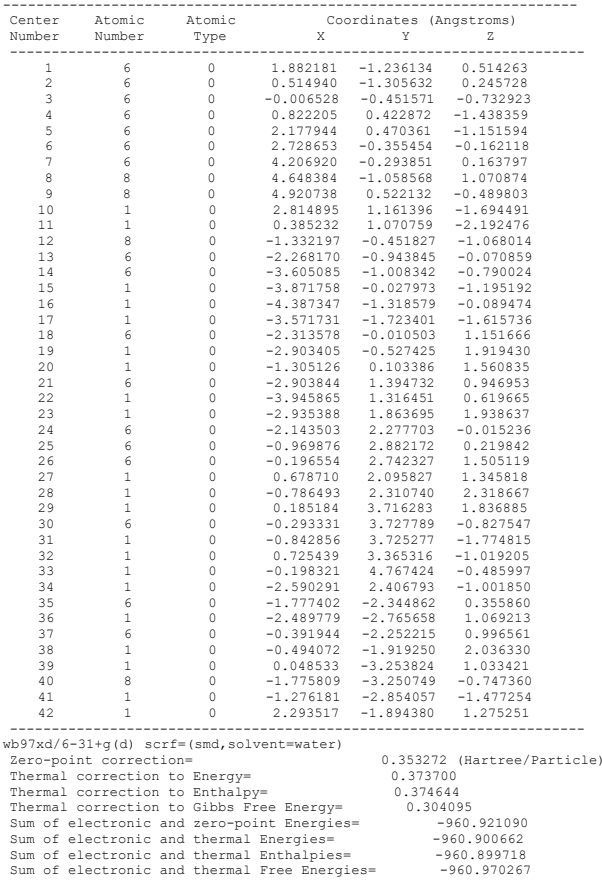

7. Furan

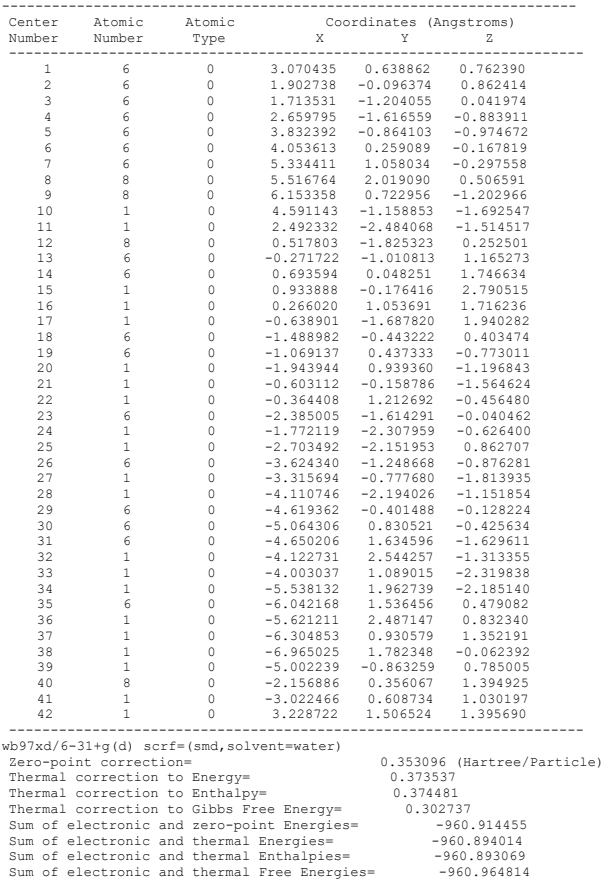

8. Fused-TS, E(donor)-H (acceptor) mode

\begin{tabular}{|c|c|c|c|c|c|}
\hline $\begin{array}{l}\text { Center } \\
\text { Number }\end{array}$ & $\begin{array}{l}\text { Atomic } \\
\text { Number }\end{array}$ & $\begin{array}{l}\text { Atomic } \\
\text { Type }\end{array}$ & $x^{\text {coo }}$ & $\begin{array}{l}\text { rdinates } \\
\text { Y }\end{array}$ & $\begin{array}{l}\text { ingstroms) } \\
\mathrm{z}\end{array}$ \\
\hline 1 & 6 & 0 & -2.859899 & 0.819094 & -4.376638 \\
\hline & & 0 & -3.331614 & 1.769845 & -4.106883 \\
\hline & & 0 & -3.616651 & 0.032330 & -4.341641 \\
\hline & ${ }_{7}^{6}$ & $\begin{array}{l}0 \\
0\end{array}$ & $\begin{array}{l}-1.7591100 \\
-0.690500\end{array}$ & $\begin{array}{l}0.494127 \\
1.34278\end{array}$ & $\begin{array}{l}-3.43220303 \\
-3.208452\end{array}$ \\
\hline & & 0 & $\begin{array}{l}-0.09605000 \\
-0.565404\end{array}$ & 2.254355 & -3.633247 \\
\hline & & 0 & 0.123058 & 0.816113 & -2.292991 \\
\hline & $\frac{1}{7}$ & $\begin{array}{l}0 \\
0\end{array}$ & $\begin{array}{r}1.025502 \\
-0.371023\end{array}$ & -0.361171 & $\begin{array}{l}-1.94149187 \\
-1.9318\end{array}$ \\
\hline $10^{9}$ & 1 & 0 & $\begin{array}{r}-.016973 \\
0.016\end{array}$ & $\begin{array}{l}-0.3611 \\
-0.932114\end{array}$ & $-1.14038=$ \\
\hline 11 & & $\begin{array}{l}0 \\
0\end{array}$ & $\begin{array}{l}-1.546333 \\
-2.132364\end{array}$ & $\begin{array}{l}-0.58145 \\
-1.4756\end{array}$ & $\begin{array}{l}-2.62263 \\
-2.48151\end{array}$ \\
\hline 13 & 6 & 0 & -4.153435 & 2.060977 & -1.203969 \\
\hline $\begin{array}{l}14 \\
15\end{array}$ & 1 & 0 & $\begin{array}{l}-4.669836 \\
-3.637911\end{array}$ & $\begin{array}{r}2.019684 \\
1.10584\end{array}$ & $\begin{array}{l}-0.23980 \\
-1.3511\end{array}$ \\
\hline 16 & 6 & 0 & $\begin{array}{r}-3.176298 \\
-3\end{array}$ & $\begin{array}{l}3.234178 \\
3\end{array}$ & -1.264298 \\
\hline $\begin{array}{l}17 \\
18\end{array}$ & 1 & 0 & $\begin{array}{l}-2.693512 \\
-3.725803\end{array}$ & $\begin{array}{r}3.282443 \\
4.176234\end{array}$ & $\begin{array}{l}-2.245180 \\
-1.1310\end{array}$ \\
\hline
\end{tabular}

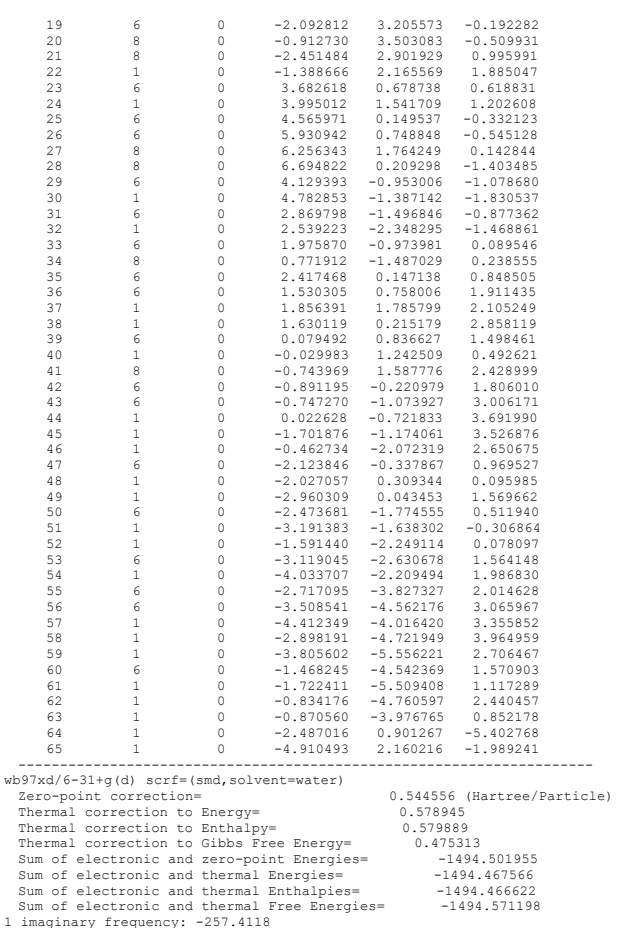

9. Spiro-TS, E(donor)-H (acceptor) mode

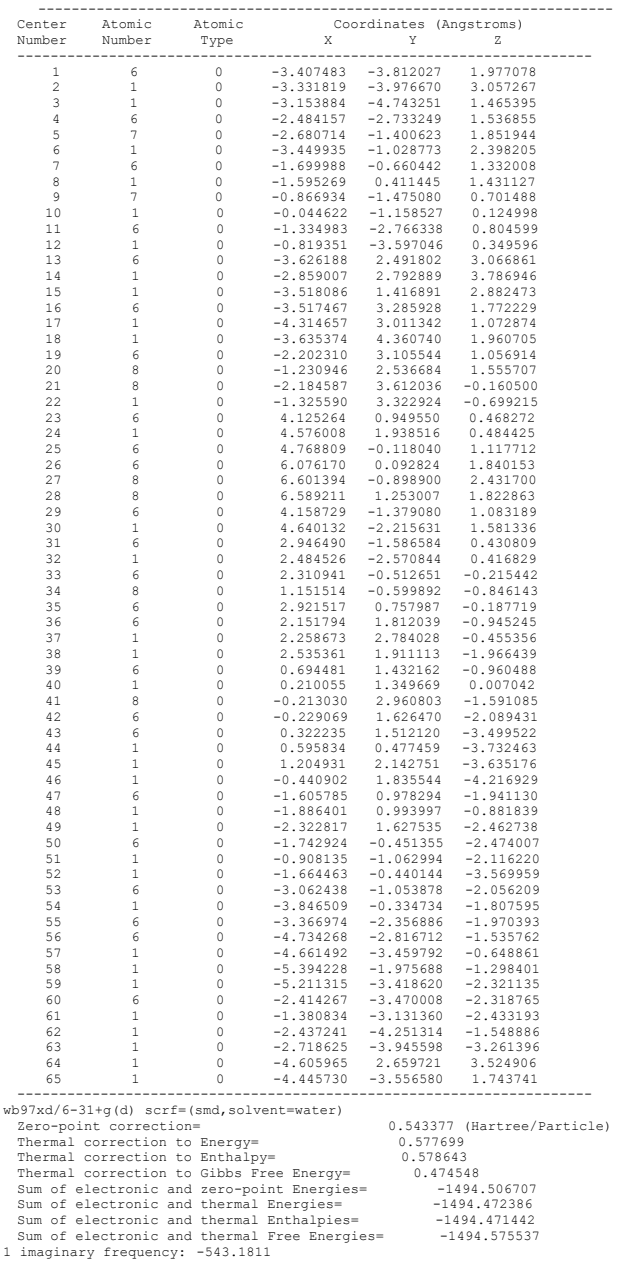

10. Fused-TS, H(donor)-E (acceptor) mode

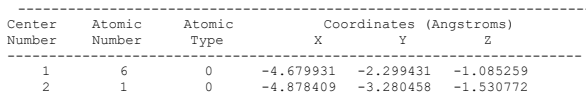




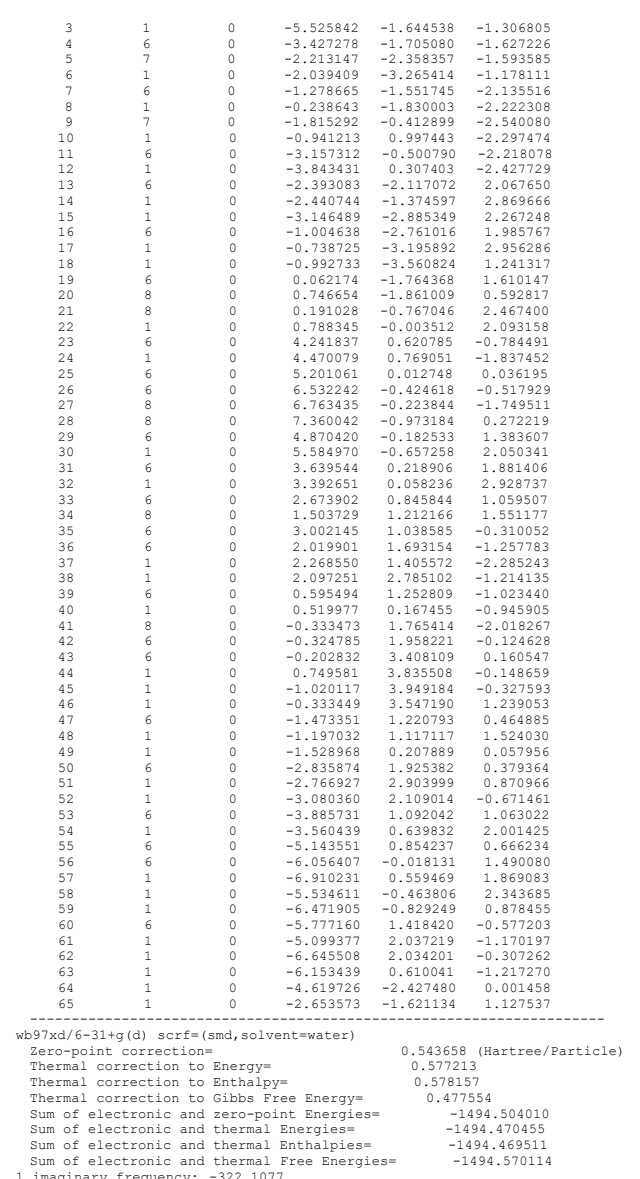

11. Spiro-TS, H(donor)-E (acceptor) mode

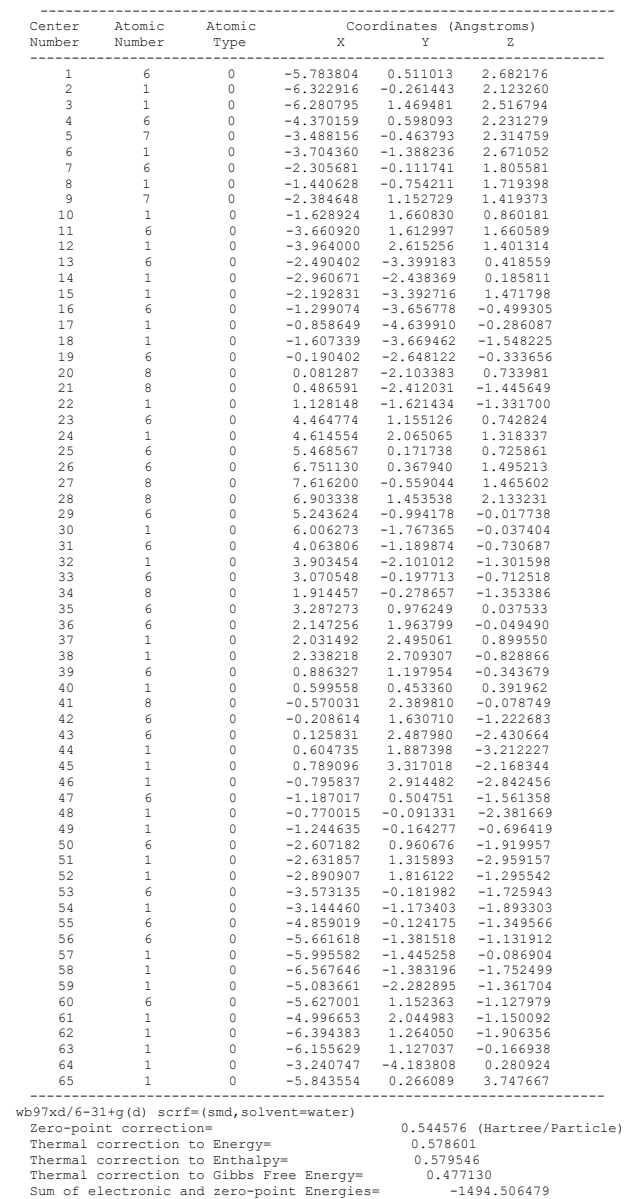

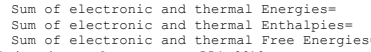

-1494.472453
-1494.471509
-1494.573925

12. Fused-TS, Y(donor)-H (acceptor) mode

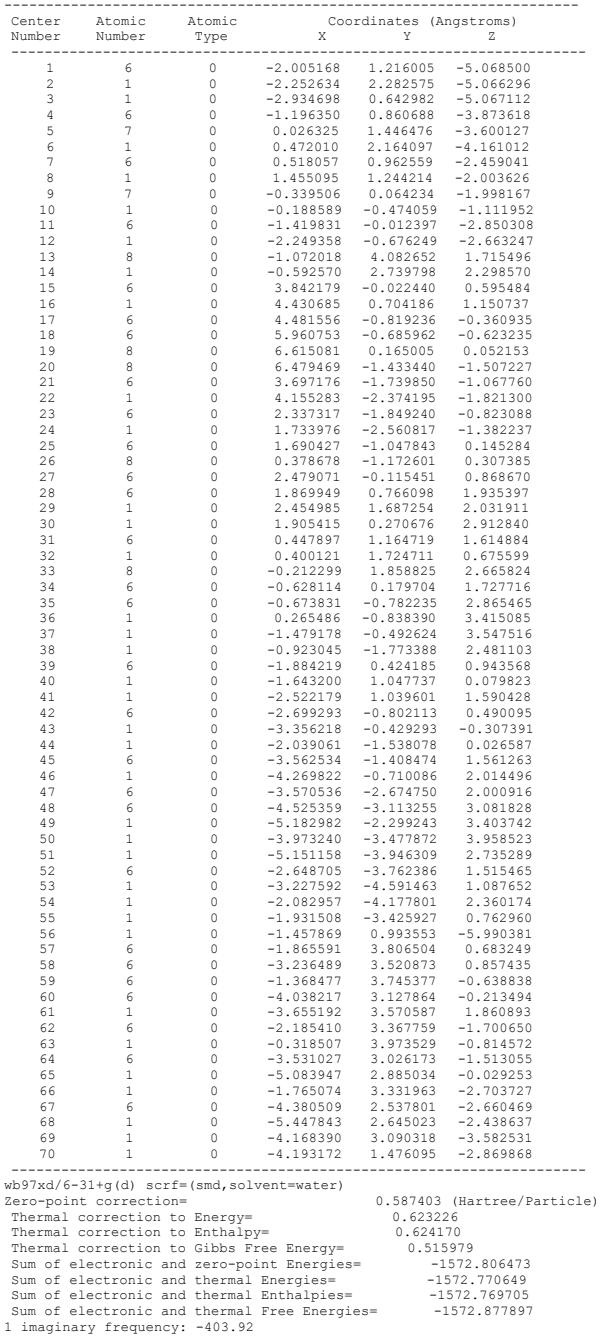

13. Spiro-TS, Y(donor)-H (acceptor) mode

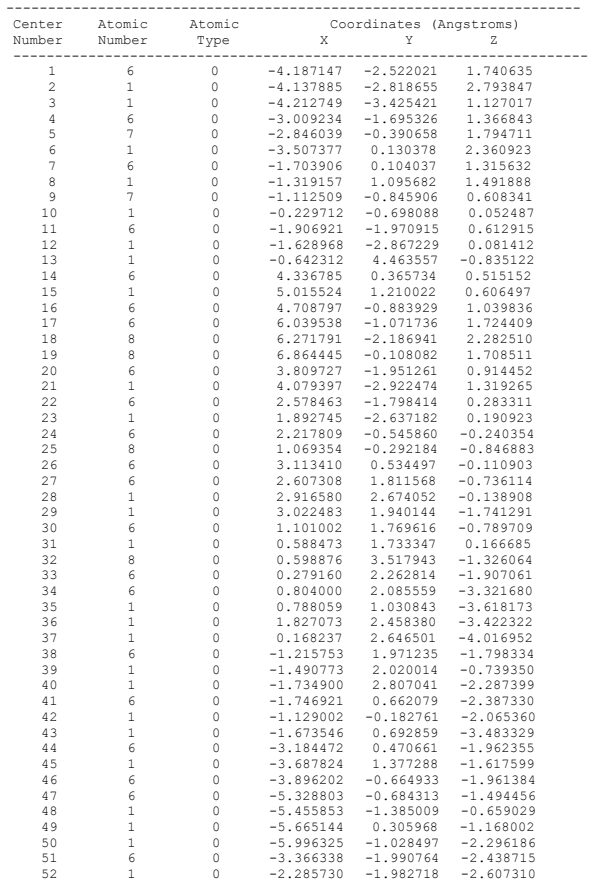




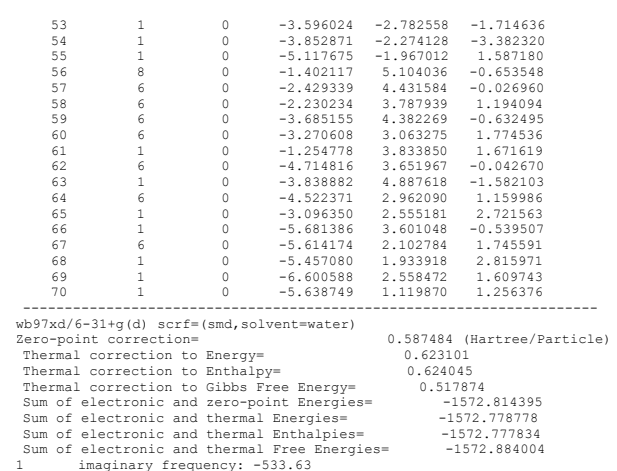

14. Fused-TS, H(donor)-Y (acceptor) mode

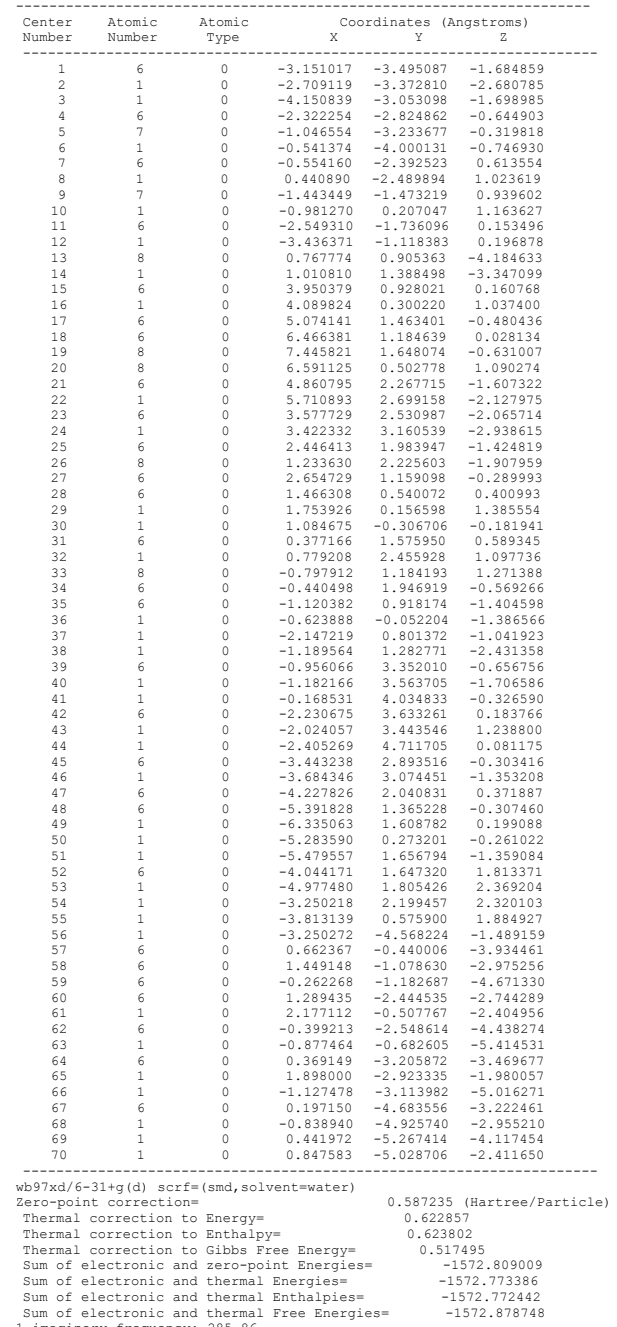

15. Spiro-TS, H(donor)-E (acceptor) mode

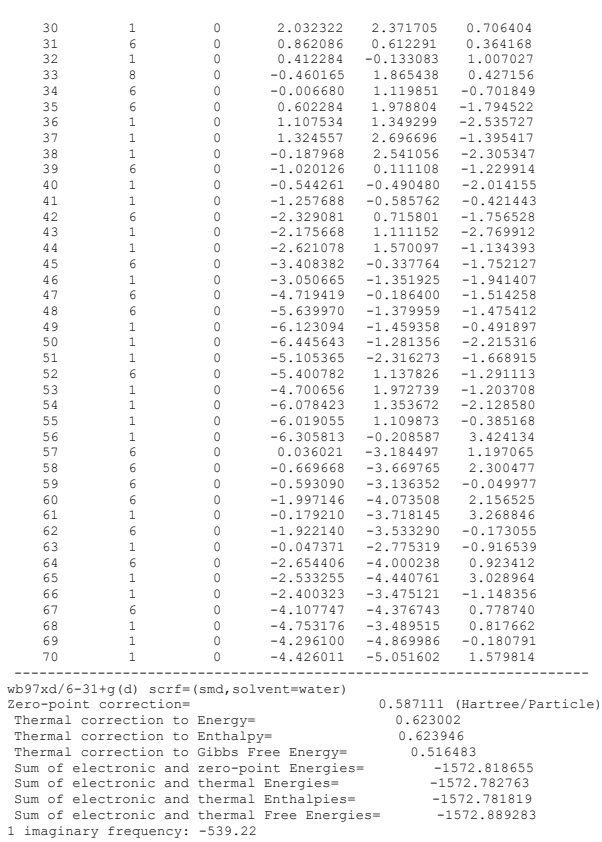

$\begin{array}{ll}\text { Sum of electronic and thermal Enthalpiese } & -1572.781839 \\ \text { Sum of electronic and thermal Free Energies } & -1572.88928 \\ \text { imaginat } & \end{array}$

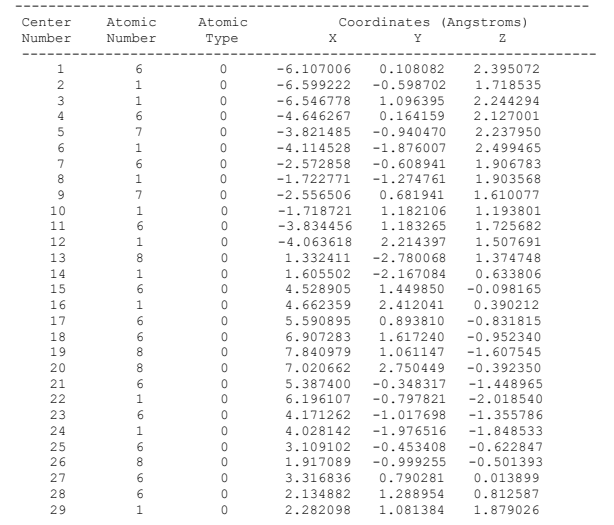

